\title{
Second-line combination therapies in nonsmall cell lung cancer without known driver mutations
}

\author{
Maria-Virginia Bluthgen and Benjamin Besse
}

Affiliation: Dept of Cancer Medicine, Gustave Roussy, Villejuif, France.

Correspondence: Benjamin Besse, Dept of Cancer Medicine, Gustave Roussy, 114 Rue Edouard Vaillant, 94805 Villejuif, France. E-mail: benjamin.bessedgustaveroussy.fr

ABSTRACT In advanced nonsmall cell lung cancer (NSCLC) patients, platinum-based combination chemotherapy is standard treatment in the first-line setting; however, the large majority of patients ultimately progress. For more than a decade, single-agent therapy with docetaxel, pemetrexed or erlotinib has been the standard of care after failure with platinum salts, showing some benefit over best supportive care. Nonetheless, prognosis remains poor and new second-line strategies are urgently needed. Combinations of cytotoxic agents, including rechallenge with platinum salts, do not offer clear benefit over single-agent therapy for the majority of patients. In patients without a known tumoural oncogenic driver mutation, regimens based on combinations of targeted agents have shown promising results; however, a clear role in therapeutic management is yet to be established. Some success has been reported in recent research combining a cytotoxic agent with targeted therapies.

In this review, we summarise published data for the various strategies evaluated over the past decade in second-line treatment of NSCLC patients without a known driver mutation. We focus on combination treatments and consider future perspectives, including the need to identify predictive markers to support personalised therapeutic strategies.

@ERSpublications

Effective second-line combinations are available but need to be integrated into a global patient management strategy http://ow.ly/SnZCC

\section{Introduction}

Lung cancer is the most common cancer worldwide, with its incidence rising dramatically over the past few years. Non-small cell lung cancer (NSCLC) accounts for nearly $80 \%$ of all cases and $\sim 70 \%$ of these patients are diagnosed with advanced disease, most of whom are eligible for treatment $[1,2]$. First-line platinum-based chemotherapy offers a significant improvement over best supportive care (BSC) in terms of disease progression and survival in these patients [3]. Nonetheless, most of these patients will eventually progress and require further treatment. Many factors are taken into account when choosing further therapy, including performance status, previous treatment, histology and the presence of a driver mutation. Driver mutations are generally located in genes coding for signalling proteins in cell proliferation and survival pathways.

Currently three drugs have been approved for the treatment of advanced NSCLC in the second-line setting: docetaxel, pemetrexed and the epidermal growth factor receptor (EGFR) tyrosine kinase inhibitor (TKI) erlotinib. In 2000, SHEPHERD et al. [4] demonstrated a significant survival benefit along with an improvement of disease-related symptoms with single-agent docetaxel $\left(75 \mathrm{mg} \cdot \mathrm{m}^{-2}\right)$ compared to BSC in second-line treatment of advanced NSCLC patients with good performance status who had relapsed after

Received: March 172015 | Accepted after revision: March 302015

Conflict of interest: None declared.

Provenance: Submitted article, peer reviewed.

Copyright CERS 2015. ERR articles are open access and distributed under the terms of the Creative Commons Attribution Non-Commercial Licence 4.0. 
first-line platinum-based treatment, reporting a 1-year survival rate of $37 \%$ versus $11 \%$ for BSC. Weekly schedules of docetaxel have been explored, suggesting similar activity with a better toxicity profile; however, these schedules have never been registered [5]. In 2004, HANNA et al. [6] demonstrated equivalent efficacy outcomes with fewer side-effects under treatment with pemetrexed compared to docetaxel, leading to its approval in all-comer NSCLC patients. In a secondary analysis, pemetrexed was demonstrated to be more active in nonsquamous cell tumours, leading to its restriction to patients with nonsquamous histology [7]. The EGFR TKIs are the treatment of choice for patients with EGFR-mutated tumours in both first and subsequent lines, but their role in EGFR wild-type tumours remains controversial and is yet to be clearly established. In 2005, a placebo-controlled trial of erlotinib conducted by SHEPHERD et al. [8] in previously-treated NSCLC patients without EGFR status selection, demonstrated a 1-year survival rate of $31 \%$ with erlotinib versus $22 \%$ for the placebo group. This study led to the approval of erlotinib as secondand third-line treatment for advanced NSCLC, independent of the EGFR mutational status, which at the time was not routinely tested for. At least 10 randomised trials have compared single-agent EGFR TKIs with single-agent chemotherapy in the second-line setting, showing an improvement in progression-free survival (PFS) but not in overall survival (OS) associated with chemotherapy treatment compared with EGFR TKIs in an EGFR wild-type population [9-19]. Regardless of the EGFR status of the tumour, treating oncologists have a basic choice between docetaxel, pemetrexed or erlotinib for second-line treatment of NSCLC patients without any known driver mutations. Available evidence suggests that chemotherapy might be the best option for fit patients with performance status 0 or 1 , although in all cases it is recommended that the patient's EGFR mutational status be determined prior to selecting second-line treatment. Here we review the main second-line options beyond single-agent chemotherapy, including chemotherapy combinations, platinum rechallenging, combinations of chemotherapy with targeted or anti-angiogenic agents and combinations of targeted or anti-angiogenic agents, and also cover promising future approaches currently under development.

\section{Second-line combined chemotherapy treatment}

While combinations of cytotoxic drugs have been successful in improving efficacy over single agents in the first-line setting $[20,21]$ in the second-line setting the role of combination therapy is less clear. Three landmark phase III studies have been performed in NSCLC patients comparing docetaxel-based combination chemotherapy with docetaxel single agent in the second-line setting. TAKEDA et al. [22] evaluated 130 patients randomly assigned to receive docetaxel alone or docetaxel plus gemcitabine. There were no significant differences in response rate ( $R R) 6.8 \%$ versus $7.0 \% ; \mathrm{p}=0.71$ ), median survival (10.1 months versus 10.3 months; $\mathrm{p}=0.36$ ) or PFS ( 2.1 months versus 2.8 months; $\mathrm{p}=0.028$ ) between docetaxel alone and docetaxel plus gemcitabine, respectively, although it should be noted that the study closed prematurely due to a high incidence of interstitial lung disease in the gemcitabine arm [22]. GeBbia et al. [5] evaluated weekly docetaxel alone using the same regimen plus gemcitabine, vinorelbine or capecitabine. This randomised phase III trial showed no statistical difference between the arms; however, again the study had no statistical power because of premature closure due to slow accrual $(n=84)$. Finally, a phase III trial conducted by PALLIS et al. [23] evaluated the efficacy of docetaxel and carboplatin versus docetaxel alone in 132 patients and found a significant clinical benefit in PFS (3.33 months versus 2.60 months; $\mathrm{p}=0.012$ ), with no significant difference in OS (10.3 months versus 7.70 months; $\mathrm{p}=0.550)$.

At least five randomised phase II trials evaluating the benefit of docetaxel- or pemetrexed-based combination therapy have been conducted over the past few years; however, none have shown a benefit in terms of survival. SMIT et al. [24] performed a trial (NVALT7) comparing pemetrexed alone with pemetrexed plus carboplatin in 240 patients who had relapsed after platinum-based chemotherapy. The primary end-point was time to progression (TTP) and secondary end-points were overall response rate (ORR) and OS. The results showed a benefit in TTP favouring the combination therapy (4.2 months versus 2.8 months, hazard ratio (HR) $0.67,95 \%$ CI 2.5-3.0 months; $\mathrm{p}=0.005$ ) with no difference in median OS ( 8.0 months versus 7.6 months, HR 0.85 ; not significant). The 1 -year survival rate was $30 \%$ for both arms. A subgroup analysis based on histology revealed a longer PFS for nonsquamous histology (3.7 months versus 2.8 months), but the addition of carboplatin positively impacted PFS in both nonsquamous and squamous cell patients. Ardizzoni et al. [25] performed a phase II trial with same design, also publishing results of a pooled analysis of both trials $(\mathrm{n}=479$; GOIRC 02-2006 and NVALT7 trials). The results showed a higher response rate in the carboplatin-containing arm (15\% versus $9 \%$; OR $1.72,95 \%$ CI $0.97-3.02 ; \mathrm{p}=0.062$ ) with a non-significantly longer PFS (3.0 months versus 3.9 months; HR 0.85 , 95\% CI $0.70-1.02 ; \mathrm{p}=0.07$ ) and no difference in OS. As expected, in a subgroup analysis, an interaction between the histology and treatment was identified, with the addition of carboplatin doubling survival for squamous histology. The population of this trial was heterogeneous, with a less favourable performance status, a higher proportion of patients with adenocarcinoma histology, shorter platinum-free intervals and fewer responses to prior treatment than in the Italian GOIRC 02-2006 trial. Docetaxel with 
or without irinotecan explored in two randomised trials $(n=130$ and $n=108)$, showed no difference in terms of PFS, survival or response rate [26, 27]. In 2009, Di MAIO et al. [28] performed a meta-analysis addressing the efficacy of combined therapy. They concluded that there was no difference in OS between the two strategies ( 37.3 weeks versus 34.7 weeks for combination therapy versus single agent, respectively), but a statistically significant increase in PFS (14 versus 11 weeks, HR 0.79; $\mathrm{p}=0.0009$ ) and response rate ( $15.1 \%$ versus $7.3 \%$; $\mathrm{p}=0.0004$ ) in favour of the combination therapy, albeit with a much higher incidence of grade 3-4 haematological ( $41 \%$ versus 25\%; $\mathrm{p}<0.001)$ and nonhaematological (28\% versus $22 \%$; $\mathrm{p}=0.034$ ) adverse events. Similar findings were reported in a subsequent meta-analysis conducted in 2012 by Qi et al. [29]. Table 1 summarises the main combination chemotherapy studies. Taken together, the available evidence does not provide a clear argument supporting the use of combination chemotherapy in the second-line setting in all-comer NSCLC patients, although it could represent a reasonable option for selected fit patients.

\section{Platinum-based chemotherapy rechallenge}

In ovarian and small cell lung cancer, rechallenge with platinum-based regimens is a widely used strategy with major benefit reported in patients relapsing after $\geqslant 6$ months $[31,32]$. To date, no prospective phase III studies directly addressing this approach have been conducted in NSCLC patients. Two major phase II trials evaluating the benefit of carboplatin-pemetrexed versus pemetrexed single agent have been performed in patients previously treated with platinum-based regimens with a minimum 3-month interval since the last platinum chemotherapy. The first of them, the above-mentioned NVALT7 Dutch study [24], stratified patients on the basis of performance status, response to prior treatment and treatment-free interval ( $<6$ months versus $>6$ months). The combination therapy resulted in a $33 \%$ reduction in the risk of progression. The majority of responding patients had responded to their first-line cisplatin-based chemotherapy, and survival was higher in patients with prior treatment $>6$ months before randomisation $(\mathrm{p}=0.001)$ [24]. The GOIRC trial included patients with $\geqslant 4$ weeks since completion of prior chemotherapy, and stratified them for the same factors as the NVALT7 trial but according to a shorter treatment-free interval ( 3 months versus $>3$ months). In the pooled analysis of both trials, neither prior response to platinum treatment nor longer treatment-free interval were predictive of improved efficacy. The Dutch trial included patients with more responses and longer platinum-free intervals with prior treatments [25].

A number of smaller phase II single-arm studies, retrospective trials and prospective series evaluating the benefit of platinum re-challenge were reviewed in a pooled analysis conducted by Petrelli et al. [32]. 607 patients with relapsed NSCLC after platinum-based chemotherapy who were rechallenged with platinum and taxanes or pemetrexed combined therapies were included in this analysis. The response rate of patients with second-line therapy was $27.5 \%$, with a median PFS of 3.9 months and median OS of

TABLE 1 Combination versus single-agent chemotherapy trials in second-line nonsmall cell lung cancer

First author, year [ref] Phase Patients
Arms

months

p-value mo

\begin{tabular}{|c|c|c|c|c|c|c|c|c|c|}
\hline Pallis, 2010 [23] & III & 132 & $\begin{array}{c}\text { Docetaxel + carboplatin } \\
\text { Docetaxel }\end{array}$ & $\begin{array}{l}3.33 \\
2.60\end{array}$ & 0.012 & $\begin{array}{l}10.3 \\
7.70\end{array}$ & 0.55 & $\begin{array}{c}10.4 \\
7.7\end{array}$ & 0.764 \\
\hline TAKEDA, 2009 [22] & III & 130 & $\begin{array}{c}\text { Docetaxel + gemcitabine } \\
\text { Docetaxel }\end{array}$ & $\begin{array}{l}2.8 \\
2.1\end{array}$ & 0.028 & $\begin{array}{l}10.3 \\
10.1\end{array}$ & 0.36 & $\begin{array}{l}7.0 \\
6.8\end{array}$ & 0.71 \\
\hline GebBiA, 2009 [5] & III & 84 & $\begin{array}{c}\text { Docetaxel } \\
\text { Docetaxel + vinorelbine or } \\
\text { gemcitabine } \\
\text { Docetaxel + capecitabine }\end{array}$ & $\begin{array}{l}12.4 \text { weeks } \\
13.1 \text { weeks }\end{array}$ & $\begin{array}{l}0.44 \\
0.60\end{array}$ & $\begin{array}{c}40 \text { weeks } \\
32.6 \text { weeks }\end{array}$ & $\begin{array}{l}0.18 \\
0.90\end{array}$ & $\begin{array}{c}6.4 \\
16.7\end{array}$ & NR \\
\hline ARDIZZoNI, 2012 [25] & II & 479 & $\begin{array}{c}\text { Pemetrexed + carboplatin } \\
\text { Pemetrexed }\end{array}$ & $\begin{array}{l}3.9 \\
3.0\end{array}$ & 0.70 & $\begin{array}{l}8.7 \\
8.2\end{array}$ & 0.316 & $\begin{array}{c}15 \\
9\end{array}$ & 0.062 \\
\hline SмIт, 2009 [24] & II & 240 & $\begin{array}{c}\text { Pemetrexed + carboplatin } \\
\text { Pemetrexed }\end{array}$ & $\begin{array}{l}4.2 \\
2.8\end{array}$ & 0.005 & $\begin{array}{l}8.0 \\
7.6\end{array}$ & NS & $\begin{array}{l}9 \\
4\end{array}$ & NS \\
\hline Pectasides, 2005 [26] & II & 130 & $\begin{array}{c}\text { Docetaxel + irinotecan } \\
\text { Docetaxel }\end{array}$ & $\begin{array}{l}5.6 \\
4.8\end{array}$ & 0.065 & $\begin{array}{l}6.5 \\
6.4\end{array}$ & 0.49 & $\begin{array}{l}20 \\
14\end{array}$ & 0.36 \\
\hline WACHTERS, 2005 [27] & II & 108 & $\begin{array}{c}\text { Docetaxel + irinotecan } \\
\text { Docetaxel }\end{array}$ & $\begin{array}{l}15 \text { weeks } \\
18 \text { weeks }\end{array}$ & 0.42 & $\begin{array}{l}27 \text { weeks } \\
32 \text { weeks }\end{array}$ & 0.69 & $\begin{array}{l}10 \\
16\end{array}$ & NR \\
\hline GeORgoulias, 2005 [30] & II & 147 & $\begin{array}{c}\text { Cisplatin + irinotecan } \\
\text { Cisplatin }\end{array}$ & NR & NR & $\begin{array}{l}7.8 \\
8.8\end{array}$ & 0.934 & $\begin{array}{c}22.5 \\
7\end{array}$ & 0.012 \\
\hline
\end{tabular}

Data are presented as n, unless otherwise stated. PFS: progression-free survival; OS: overall survival; NR: not reported; NS: nonsignificant. 
8.7 months. Response rate was independent of response to first-line treatment $(p=0.24)$. Analysis of the platinum-free interval period could not be performed due to insufficient data. However, they found that in trials where the majority of patients had a TTP $>6$ months, the response rate was $>40 \%$. Response rate was also better in studies including patients with at least two prior lines of treatment, suggesting that time since the last platinum-based therapy may influence response [33].

The available evidence suggests that platinum rechallenge could represent a valid option for relapsed fit patients with a platinum-free interval treatment of $>6$ months. Nonetheless, in the absence of a proven role for this strategy, prospective phase III trials should be conducted to definitively address this issue.

\section{Second-line combined treatment with chemotherapy and targeted/anti-angiogenic therapy}

Identification of patients who are likely to respond better to therapy is the underlying basis of personalised treatment, and to this end many predictive biomarkers have been identified over the past decade. In NSCLC, the main oncogenic driver mutations that can serve as therapeutic targets are the growth factor receptors EGFR, human epidermal growth factor receptor (HER)2 and BRAF, along with anaplastic lymphoma kinase $(A L K)$ rearrangements. An increasing number of trials have evaluated the benefit of a combination of chemotherapy with targeted therapy in advanced NSCLC patients with either wild-type EGFR or who are unselected for mutational status. Positive outcomes have only been seen when the targeted agent is combined with docetaxel.

\section{EGFR pathway inhibitors}

EGFR is a member of the Erb family of transmembrane tyrosine kinase receptors which, after ligand binding, activates an intracellular cascade of events resulting in cell proliferation and survival. Targeting of the EGFR pathway with erlotinib, a first-generation oral inhibitor of this tyrosine kinase, first demonstrated a survival benefit in second-line therapy in unselected patients in 2005 [8]. Almost 10 years later, LeE et al. [34] conducted a three-arm randomised phase II trial comparing the efficacy of combination standard second-line therapies with pemetrexed and erlotinib to either pemetrexed or erlotinib alone $(n=240)$. Combination therapy significantly prolonged PFS over either single agent (7.4 months versus 3.8 months with erlotinib, HR $0.57 ; \mathrm{p}=0.002$ versus 4 months with pemetrexed, HR 0.58; $\mathrm{p}=0.005)$. EGFR status was analysed in only $22 \%$ of the patients, so few patients could be confirmed as wild type. Patients had a high probability of having EGFR-mutated NSCLC since the proportions of never-smokers and of Asian ethnicity were both high. In the EFGR wild-type subgroup $(n=19)$, the benefit of the combination was superior, in terms of PFS, to either agent alone.

A similar trial conducted by DIтTRICH et al. [35] evaluating combination therapy with pemetrexed and erlotinib versus pemetrexed alone in 165 nonsquamous cell patients with unknown EGFR mutational status, showed a small but significant benefit in PFS (2.89 months for pemetrexed versus 3.19 months for pemetrexed/erlotinib, HR 0.63; $\mathrm{p}=0.005)$ and in OS (7.75 months for pemetrexed versus 11.8 months for pemetrexed/erlotinib, HR $0.68 ; \mathrm{p}=0.019$ ). While the pemetrexed-alone arm performed as expected, it should be kept in mind that survival may be influenced by subsequent lines of treatment, which were for the most part unknown.

Several monoclonal antibodies targeting EGFR have been evaluated in NSCLC. A phase III study conducted by KIM et al. [36] found no benefit of adding cetuximab (which binds to the extracellular domain of EGFR) to standard second-line chemotherapy with pemetrexed or docetaxel, in terms of OS, PFS or response rate, regardless of EGFR status and histology, and was associated with more adverse events ( $\mathrm{n}=939$ ). Matuzumab, an IgG1 monoclonal antibody against the EGFR-binding domain with a longer half-life than cetuximab, has demonstrated activity in preclinical studies [37, 38], resulting in further evaluation in the clinic. Combination second-line therapy of matuzumab with pemetrexed was evaluated in a phase II study $(\mathrm{n}=148)$ in 2010 by Schiller et al. [39]. The results showed a trend for improved survival and a rate response benefit with an acceptable toxicity profile in patients with EGFR-expressing tumours. A novel EGFR recombinant monoclonal fully human antibody, necitumumab, has been evaluated in squamous NSCLC patients in combination with standard chemotherapy in the phase III SQUIRE trial [40]. The primary end-point of improved survival in the first-line setting was met, so that necitumumab efficacy could be investigated in the second-line setting. However, there was no improvement in OS with the addition of necitumumab to first-line pemetrexed-cisplatin in metastatic nonsquamous cell NSCLC patients [41].

\section{Blocking the RAS/RAF/MEK/extracellular signal-regulated kinase pathway}

$\mathrm{K}$-Ras and BRAF are downstream of EGFR in this signalling pathway. $K$-Ras mutations are present in $\sim 15-30 \%$ of all NSCLC tumours. It has been postulated that constitutive activation of K-Ras leads to cell proliferation irrespective of EGFR inhibition, predicting a lack of benefit with EGFR inhibitors and poorer 
survival [42, 43]. A phase II trial in the second-line setting evaluating docetaxel combined with selumetinib, an inhibitor of MEK1-MEK2 downstream of K-Ras, showed a significant benefit for PFS and response rate in K-Ras-mutated NSCLC patients [44]. However, the docetaxel arm did not perform as expected (PFS 5.3 months versus 2.1 months; HR 0.58, $\mathrm{p}=0.014$; rate response $37.2 \%$ versus $0 \%$ ) and the treatment groups were not well balanced. Although to date there are no approved drugs for K-Ras-mutated NSCLC patients, selumetinib seems to be a promising option meriting further research.

\section{Antibodies against the vascular endothelial growth factor pathway}

Angiogenesis is essential for tumour growth and proliferation. Targeting anti-angiogenic pathways with bevacizumab, a human monoclonal antibody binding vascular endothelial growth factor (VEGF), in combination with carboplatin-taxane chemotherapy as first-line treatment, demonstrated a survival benefit in nonsquamous cell NSCLC patients [45]. Bevacizumab was then evaluated in the second-line setting and beyond in nonsquamous cell patients. The single-arm phase II NCCTG/SWOG study N0426 gave a PFS of 4 months with combined pemetrexed and bevacizumab, although the primary end-point was not reached because of a low number of events referring to the primary end-point [46]. In a phase II trial conducted by Herbst et al. [47] bevacizumab was evaluated in combination with second-line chemotherapy (pemetrexed or docetaxel) or with erlotinib versus chemotherapy alone in nonsquamous cell patients unselected for EGFR status. The results showed superior survival with both bevacizumab combination therapies (1-year survival rate of $53.8 \%$ for bevacizumab plus pemetrexed/docetaxel versus $57.4 \%$ with bevacizumab plus erlotinib versus $33.1 \%$ with chemotherapy alone). A retrospective analysis of the efficacy of the combination therapy of bevacizumab and weekly paclitaxel in metastatic nonsquamous NSCLC patients as fourth-line therapy and beyond $(n=20)$ showed clinical benefit in $75 \%$ of the patients with an acceptable toxicity profile [48]. Based on these promising results a large phase III trial (IFCT-1103 ULTIMATE) evaluating the efficacy of paclitaxel and bevacizumab combination therapy compared with standard docetaxel as second- or third-line therapy in 251 nonsquamous cell NSCLC patients is ongoing (NCT01763671). Aflibercept is a recombinant human fusion protein targeting the extracellular domains of the VEGF receptors (VEGFR) 1 and 2, which is approved for treatment of pre-treated colorectal cancer patients. It was recently evaluated in combination with docetaxel versus docetaxel alone in 913 platinum pre-treated advanced NCSLC patients in a phase III trial conducted by RAMLAU et al. with OS as the primary end-point [49]. Combination therapy did not improve survival, but did prolong PFS (5.2 months versus 4.1 months, $\mathrm{p}=0.0035)$ and $\mathrm{ORR}(23.3 \%$ versus $8.9 \%, \mathrm{p}<0.001)$ compared to standard second-line chemotherapy alone, and had a similar toxicity profile to other VEGFR-targeted therapies.

Additional studies have been conducted with novel anti-angiogenic drugs including ramucirumab, a fully humanised IgG1 antibody that targets the extracellular domain of VEGFR2. The REVEIL trial conducted by GARON et al. [50] evaluated the addition of ramucirumab to conventional docetaxel therapy versus docetaxel plus placebo $(n=1253)$. Overall, $14 \%$ of patients had been pre-treated with bevacizumab in the experimental arm. Of note, $17 \%$ of the patients were never-smokers and $25 \%$ were squamous NSCLC patients. The results showed prolonged OS (10.5 months versus 9.1 months; HR 0.86, $\mathrm{p}=0.023$ ), the primary end-point, and PFS (4.5 months versus 3.0 months; HR 0.76, p<0.0001) in the ramucirumab group. The control group performed as expected, although patients with performance status 2 and those at high risk for anti-angiogenic therapy were excluded. No differences in benefit were seen for females or squamous cell patients, although the study was not powered for subgroup analysis.

\section{Multitarget agents encompassing the VEGF pathway}

A number of anti-angiogenic agents targeting multiple cell receptors have been evaluated in the second-line NSCLC setting in combination with chemotherapy. DE BoER et al. [51] assessed vandetanib, an oral inhibitor of EGFR/VEGFR/RET, combined with pemetrexed compared to pemetrexed plus placebo in 534 pre-treated patients, reporting a nonsignificant benefit in PFS and OS, although with a modest, albeit significant, benefit in ORR $(19.1 \%$ versus $7.9 \%, \mathrm{p}<0.001)$ in the combination arm. This trial did not meet its primary end-point. More encouraging results were reported when vandetanib was combined with docetaxel in the large-scale ZODIAC trial $(\mathrm{n}=1391)$ conducted by HerbsT et al. [52]. Significant improvements in PFS, the primary end-point (4.0 months versus 3.2 months; $H R=0.79, p<0.0001$ ), response rate $(17 \%$ versus $10 \%, \mathrm{p}=0.0001)$ and time to deterioration of symptoms were seen with the addition of vandetanib to conventional treatment, although no differences in any of the subgroup analyses, including females, were found, in contrast to previously reported phase II findings [53]. A retrospective analysis of potential biomarkers predictive of benefit with vandetanib showed that greater clinical benefit was seen in patients with EGFR-mutated tumours (PFS: HR 0.51, 95\% CI 0.25-1.06 and OS: HR 0.46, 95\% CI 0.14-1.57) and EGFR fluorescence in situ hybridisation (FISH)-positive tumours (PFS: HR 0.61, 95\% CI $0.39-0.94$ and OS: HR 0.48, 95\% CI 0.28-0.84); K-Ras-mutated tumour patients did not benefit from combined therapy [54]. 
The combination of pemetrexed with nintedanib, an oral inhibitor of VEGFR1-3, fibroblast growth factor receptor 1-3, platelet-derived growth factor receptor (PDGFR), RET, FLT3 and Src, compared to single-agent chemotherapy, was evaluated by HANNA et al. [55]. The LUME-Lung 2 trial $(n=713)$ has been terminated prematurely following a preplanned futility analysis of PFS which showed an absence of any benefit, although a posterior analysis revealed a small benefit in PFS with the combination arm (4.4 months versus 3.6 months; $\mathrm{p}=0.0435$ ). The LUME-Lung 1 trial, conducted by ReCK et al. [56] evaluated the addition of nintedanib to conventional docetaxel therapy in 1314 patients. Patients were stratified by performance status, previous bevacizumab $(n=27,4.1 \%)$, brain metastases and histology. Results demonstrated a significant improvement in the primary end-point of PFS (3.5 months versus 2.7 months, HR 0.85; $\mathrm{p}=0.007$ ) in all predefined subgroups. OS was significantly longer among patients progressing within 9 months (10.9 months versus 7.9 months, HR $0.75 ; \mathrm{p}=0.0073$ ) and in the adenocarcinoma group (12.6 months versus 10.3 months, HR $0.83 ; \mathrm{p}=0.0359$ ) treated with docetaxel plus nintedanib, although no difference was seen in the overall patient population or in patients with squamous cell carcinoma. Subsequent treatment was balanced between the two groups and the control group performed as reported in other phase III trials [4, 6]. Table 2 summarises the major studies reporting chemotherapy combined with targeted agents. Taking into account the aforementioned data, integrating anti-angiogenic agents into the therapeutic strategy for adenocarcinoma, a known effective approved option in the first-line setting, also represents a potentially valid option in the second-line setting.

\section{Second-line treatment with combined targeted and anti-angiogenic therapy}

Combining therapies targeting different molecular markers in a given signalling pathway is a logical strategy for overcoming resistance mechanisms to obtain survival benefits with fewer adverse events. Several trials have been conducted to evaluate the potential benefit of combining targeted agents, notably with agents targeting the EGFR and VEGF pathways. HerbST et al. [47] in 2007, in the previously cited phase II trial,

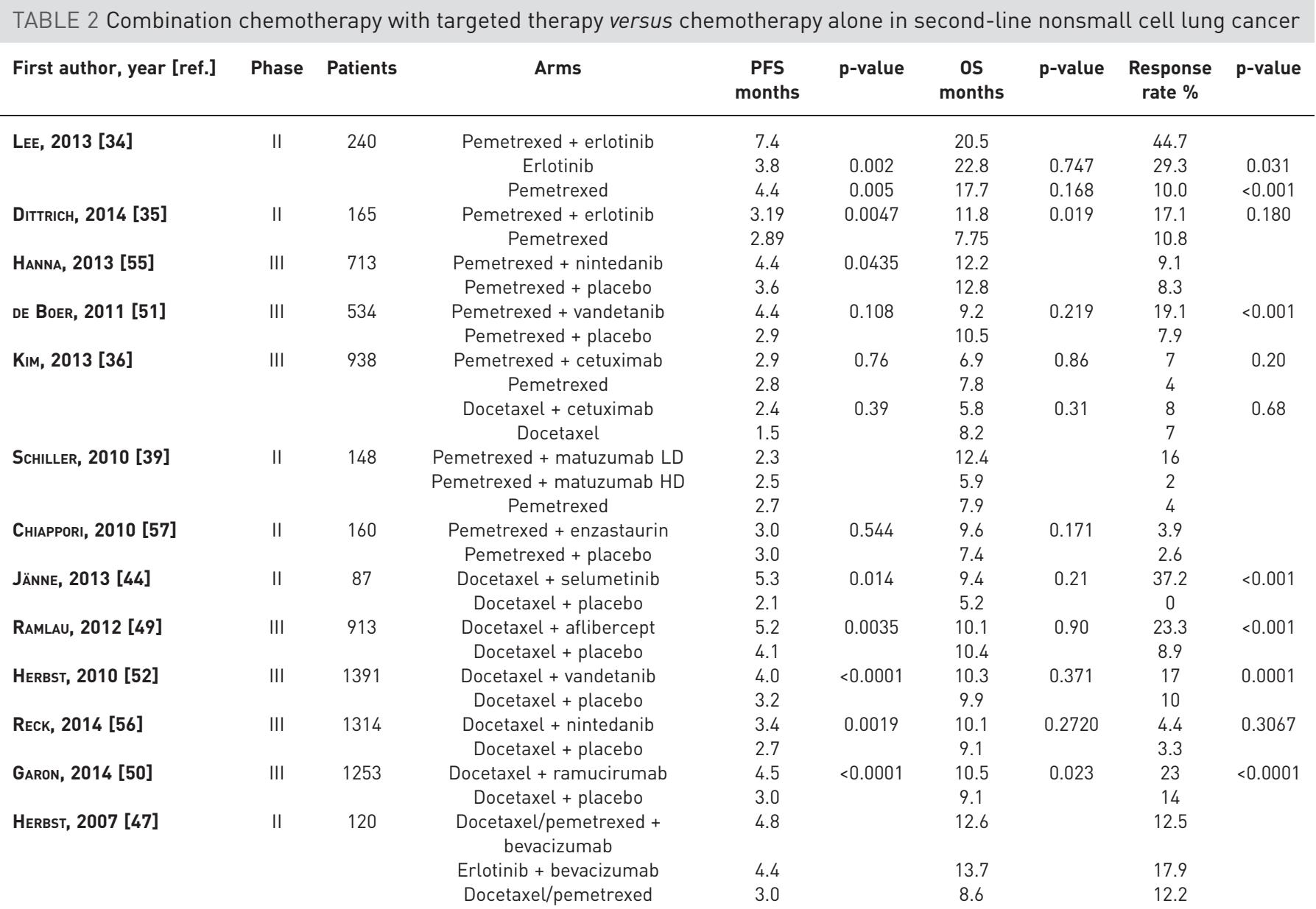

Data are presented as n, unless otherwise stated. PFS: progression-free survival; OS: overall survival; LD: low dose; HD: high dose. 
evaluated the combination of erlotinib and bevacizumab, along with standard chemotherapy. Median OS was better with combined erlotinib and bevacizumab compared to chemotherapy alone (13.7 months versus 8.6 months, respectively), along with a better safety profile. However, a phase III trial conducted by the same group comparing combined erlotinib and bevacizumab versus erlotinib plus placebo in 636 nonsquamous cell NSCLC refractory patients, where $>90 \%$ of the patients were EGFR wild-type and $>75 \%$ were $K$-Ras wild-type, gave conflicting results. No significant difference was seen for the primary end-point (HR 0.97, p=0.7583), although a nonsignificant trend for benefit in PFS and response rate was apparent. Subgroup analysis did not identify statistical significance nor any predictive biomarkers [58].

Sunitinib, an oral tyrosine kinase inhibitor of VEGFR-PDGFR-KIT-FTL3-RET, has demonstrated some activity in phase II studies in NSCLC refractory patients [59]. This agent was evaluated in combination with erlotinib versus erlotinib plus placebo, targeting dual signalling by the EGFR and angiogenic pathways. EGFR status was unknown in $>90 \%$ of the patients in both groups, but the majority of patients included were neither Asian nor never-smokers. The results show similar OS for both groups ( 9.0 months versus 8.5 months; HR 0.92, p=0.0471), PFS was 3.6 months versus 2.0 months (HR 0.80, $\mathrm{p}=0.0023$ ) and response rate was $10.6 \%$ versus $6.9 \%(\mathrm{p}=0.471)$ for combination therapy and erlotinib plus placebo treatment, respectively. The incidence of grade 3 toxicity was higher in the combination group [60]. Sorafenib, another multikinase inhibitor of VEGFR 2,3-PDGFR-RAF1-FLT3-cKIT that has demonstrated clinical benefit in NSCLC [61] and may represent, when combined with erlotinib, a means of dual inhibition of major lung cancer targets. SPIGEL et al. [62] conducted a phase II trial evaluating erlotinib in combination with sorafenib versus erlotinib plus placebo. In EGFR wild-type tumours, median PFS was 3.38 months for combination therapy versus 1.77 months for erlotinib plus placebo $(\mathrm{p}=0.018)$, median OS was 8.0 months versus 4.5 months $(\mathrm{p}=0.019)$ and response rate was $14 \%$ versus $0 \%$, respectively, with similar results in EGFR FISH-negative patients. K-RAS was not found to be a good predictive biomarker in any subgroup. Although some benefits in EFGR wild-type and EGFR FISH-negative patients may merit further studies, it is important to note that combination treatment increased haematological, gastrointestinal, skin toxicity and general disorders. Furthermore, patient characteristics were not well balanced and the small number of patients in the control group makes it difficult to draw definitive conclusions.

The mammalian target of rapamycin (mTOR) is a serine-threonine kinase downstream of the phosphoinositide 3-kinase (PI3K)/AKT/PTEN (phosphatase and tensin homologue) pathway, regulating cell growth and proliferation. The PI3K/AKT/PTEN/mTOR pathway is thought to be activated in NSCLC and provides a possible mechanism of resistance to EGFR TKIs [63, 64]. It has consequently been postulated that combination therapy of EGFR TKIs and mTOR inhibitors may be beneficial in this setting. Inhibition of this molecular target with everolimus, an oral mTOR inhibitor, has shown some activity in NSCLC as single agent, and has been studied in combination with EGFR TKIs for chemotherapy refractory NSCLC patients. In 2010, PRICE et al. [65] performed a phase II study evaluating the combination of gefitinib and everolimus in NSCLC in the first- and second-line settings, reporting a response rate of $9.6 \%$ and median OS of 11 months in pre-treated patients with a 1-year survival rate of $39 \%$. In a phase II trial published in 2014 by BESSE et al. [66], combination of erlotinib and everolimus treatment showed no benefit in terms of survival or PFS over erlotinib plus placebo, with an increased incidence of grade 3-4 events $(72.7 \%$ versus $32.3 \%$, and $31.8 \%$ grade $3-4$ stomatitis with combination therapy). EGFR status was not assessed. On the basis of these trials, combination therapy did not add worthwhile benefit to EGFR TKIs in unselected populations.

The binding of ligand to the c-MET tyrosine kinase receptor activates downstream signalling involving the RAS pathway, promoting cell growth and proliferation. MET deregulation can be caused by overexpression, amplification or mutation, and has been found in several malignancies, including NSCLC, and predicts both resistance to EGFR TKIs and poorer survival [67]. Tivantinib, an oral MET inhibitor, was evaluated in a phase II study conducted by SEQUIST et al. [68] in combination with erlotinib in pre-treated NSCLC patients showing no survival benefit compared to erlotinib plus placebo. A significant PFS benefit was reported in $K$-Ras-mutated patients ( $H R$ 0.18, p<0.01). The phase III trial $(\mathrm{n}=1048)$ failed to meet its primary end-point in the total patient population (HR 0.98, $\mathrm{p}=0.81)$, but did show benefit in the subset of patients with MET expression (2+ positive MET immunostaining in $>50 \%$ of tumour cells) with the combination therapy (HR 0.45, c-MET FISH >5) [69]. A humanised monovalent monoclonal antibody against the MET receptor, onartuzumab, has given modest benefit in combination with erlotinib in patients with high MET expression; the ongoing METLung phase III trial is evaluating this combination in patients with high MET expression in the second-line setting, and results should be available soon (NCT01456325). Other studies of combined erlotinib therapy over erlotinib plus placebo have been conducted, but none of them reported a benefit in terms of OS and PFS [70-72]. Table 3 summarises combination therapies with targeted and anti-angiogenic agents in second-line NSCLC. 
TABLE 3 Combination therapy with targeted and anti-angiogenic agents in second-line nonsmall cell lung cancer

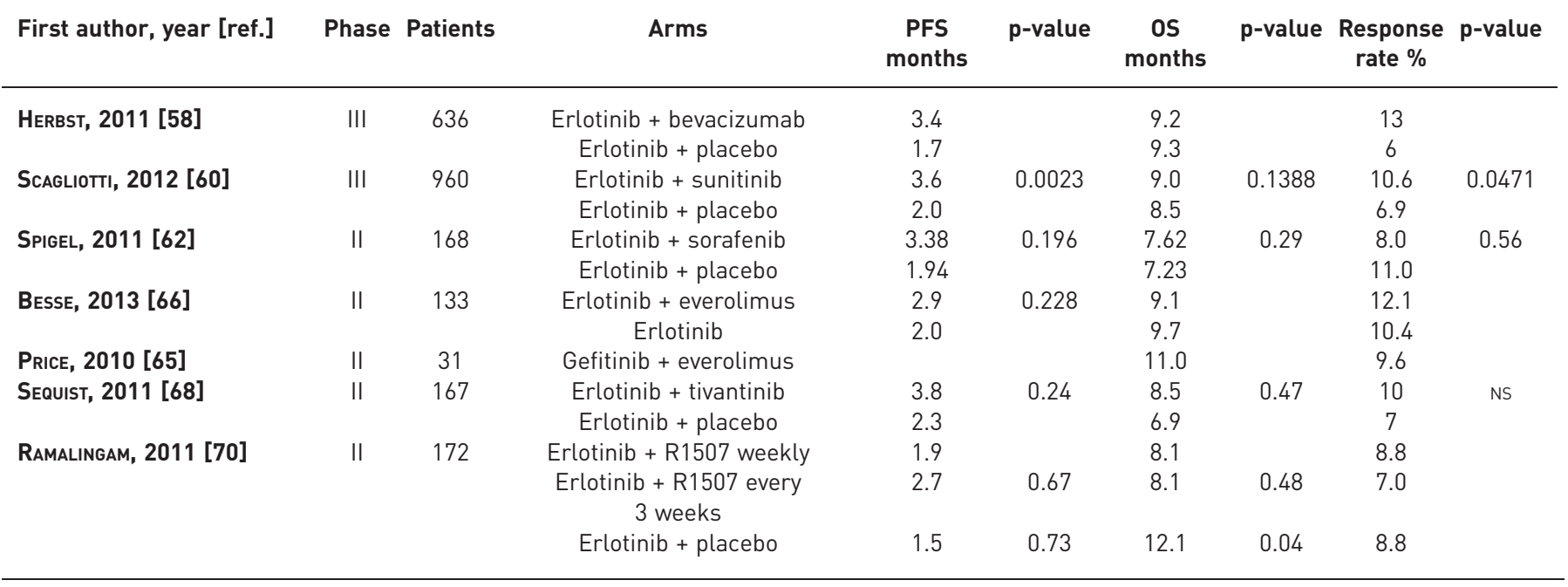

Data are presented as n, unless otherwise stated. PFS: progression-free survival; OS: overall survival; NS: non significant.

A recent meta-analysis of published data conducted by Qi et al. [73] evaluating combined targeted agents versus single-agent erlotinib, found benefits in OS (HR 0.9, p=0.024) and PFS (HR 0.83, p=0.018) favouring combination therapy over erlotinib alone, in EGFR wild-type and K-Ras-mutated patients. However, given that mutational status was rarely reported along with the limitations of a meta-analysis based on non-individual patient data, results must be interpreted with caution. In summary, combined targeted therapy may be a promising strategy in unselected NSCLC patients. Outcomes appear to be linked to mutational status, making identification of predictive biomarkers for patients more likely to benefit from the various target agents a crucial aspect of the treatment strategy for NSCLC.

\section{Future perspectives}

Over the past decade, evolving and improving knowledge of lung cancer biology has changed the previous paradigm based on histology-oriented treatment to one based on biomarker-driven therapy. To date, targeted therapy is restricted to only a few biomarkers, notably EGFR mutations and ALK/ROS1 translocations. Additional drivers have been described and are being explored in NSCLC, such as BRAF V600E mutations (2\%) that can be targeted with vemurafenib or dabrafenib [74], and mutations in HER2 (3\%) [75]. Thus, a proportion of patients who are qualified today as wild-type NSCLC may well be reclassified tomorrow and treated with specific targeted agents. In terms of moving towards a personalised therapy approach, there are several upcoming screening programmes using tumoural molecular profiling to guide patients as to access clinical trials using targeted therapies, such as the European Organisation for Research and Treatment of Cancer SPECTAlung (Screening Patients with thoracic tumors for Efficient Clinical Trial Access) study (NCT02214134).

Immunotherapy is another area of ongoing research that represents an alternative treatment approach for NSCLC patients. Evolving knowledge of the immune environment of lung cancer had led to NSCLC being considered an immunological targetable disease, with the consecutive development of several new drugs targeting immune checkpoint inhibition. Numerous immune checkpoints can be blocked in order to modulate and enhance the patient's natural immune response to cancer. Cytotoxic T-lymphocyte-associated protein (CTLA)-4 and programmed cell death protein (PD)-1 are the main targets which have been studied over the last few years. Both are expressed on activated $\mathrm{T}$ cells, and interact with ligands on antigen-presenting cells limiting the immune response.

A phase II study in the first-line setting evaluating platinum-based chemotherapy with ipilimumab, a fully humanised monoclonal antibody blocking CTLA-4, used two regimens, one concurrent and one sequential, reached the primary end-point in the ipilimumab sequential arm [76]. A prolonged immune-related PFS was seen compared with chemotherapy alone. Subgroup analysis found squamous cell patients had a greater improvement in PFS and in OS compared to those with nonsquamous histology. A confirmatory phase III trial in metastatic or recurrent squamous cell NSCLC patients is ongoing (NCT01285609). 
Nivolumab (BMS-936558), a fully humanised monoclonal IgG4 antibody blocking PD-1, gave promising responses in a phase I study conducted by Topalian et al. [77] in advanced NSCLC patients, with a $32 \%$ ORR and an OS rate of $42 \%$ at 1 year. Rizvi et al. [78] evaluated the efficacy and safety of nivolumab in 117 patients with advanced refractory squamous NSCLC in a phase II single-arm trial, with an objective response confirmed in $14.5 \%$ of the patients, a median PFS of 1.9 months and a median OS of 8.2 months, which compare favourably to historical data of single cytotoxic agent efficacy in this population. Two phase III trials evaluating nivolumab versus docetaxel in nonsquamous cell (NCT01642004) and squamous cell (NCT01673867) patients in the second-line setting have been performed. The primary objective (OS) of the later trial has been reported as met in a recent press release [79]. Nivolumab has been approved in the USA for the treatment of squamous NSCLC patients refractory to chemotherapy and expended access programmes have been open in various countries. An antibody blocking programmed death-ligand (PD-L) 1 has also shown encouraging results in a phase I trial. SoRIA et al. [80] evaluated the safety and efficacy of MPDL3280A in 53 patients, with an ORR of 24\% in all NSCLC patients, $100 \%$ in PD-L1-positive patients $(n=4)$ and $15 \%$ in PD-L1-negative patients. Higher response rates were also seen in former/current smokers compared with never-smokers, making this the first study to suggest a potential relationship with smoking status and response to inhibitors of the PD-1 pathway. A phase III trial comparing MPDL3280A with docetaxel as second-line treatment is underway (NCT02008227).

Vaccines constitute an active form of immunotherapy which can be used to treat cancer, many of which are under investigation in NSCLC. TG4010, a vaccine based on a poxvirus that codes for MUC1 tumour-associated antigen and interleukin-2, was evaluated in a phase IIb trial in combination with standard first-line chemotherapy versus chemotherapy alone, in 148 patients with NSCLC expressing MUC1. This trial showed an improvement in its primary end-point PFS compared with the control group (6 months PFS $43.2 \%$ versus $35.1 \%$, respectively) so that its activity could be explored in other settings, including combination with antibodies against PD-1 and PD-L1 [81]. A human recombinant EGF-based vaccine showed encouraging results in a phase II trial in the second-line setting with a trend towards increased survival [82]. Racotumomab, a ganglioside vaccine, is also currently being investigated in combination with docetaxel in the second-line setting (NCT01240447). Several other immunotherapies are under investigation with promising results.

\section{Conclusions}

Single-agent chemotherapy remains the most validated standard option in the second-line setting for NSCLC patients without any known driver mutations. Although combination chemotherapy treatment does not appear to prolong survival compared to single-agent therapies, it may nonetheless offer benefit in selected fit patients. Platinum rechallenge therapy only appears to be an effective approach in patients with late progression after first-line platinum chemotherapy. Integrating anti-angiogenic therapies into chemotherapeutic approaches in adenocarcinoma patients is a realistic option, although the optimal setting and sequences have yet to be defined. Combining targeted therapies result in promising efficacy but a recommended role is yet to be defined, mostly due to side-effects. A better understanding of which patients will obtain greater benefit from the different therapies and identification of reliable predictive biomarkers are critical. The continuing identification of novel oncogene drivers via improved diagnostic techniques and new-generation "liquid biopsies" which can be used to measure cell-free tumour DNA in the blood, offering a means of early detection of the tumoural mutational status, will provide the framework for the development of new targeted agents and selection of more efficient therapeutic approaches for individual patients.

\section{References}

Ettinger DS, Akerley W, Bepler G, et al. Non-small cell lung cancer. J Natl Compr Canc Netw 2010; 8: 740-801. Jemal A, Bray F, Center MM, et al. Global cancer statistics. CA Cancer J Clin 2011; 61: 69-90.

NSCLC Meta-Analyses Collaborative Group. Chemotherapy in addition to supportive care improves survival in advanced non-small-cell lung cancer: a systematic review and meta-analysis of individual patient data from 16 randomized controlled trials. J Clin Oncol 2008; 26: 4617-4625.

4 Shepherd FA, Dancey J, Ramlau R, et al. Prospective randomized trial of docetaxel versus best supportive care in patients with non-small-cell lung cancer previously treated with platinum-based chemotherapy. J Clin Oncol 2000; 18: 2095-2103.

5 Gebbia V, Gridelli C, Verusio C, et al. Weekly docetaxel vs. docetaxel-based combination chemotherapy as second-line treatment of advanced non-small-cell lung cancer patients. The DISTAL-2 randomized trial. Lung Cancer 2009; 63: 251-258.

6 Hanna N, Shepherd FA, Fossella FV, et al. Randomized phase III trial of pemetrexed versus docetaxel in patients with non-small-cell lung cancer previously treated with chemotherapy. J Clin Oncol 2004; 22: 1589-1597.

7 Scagliotti GV, Parikh P, von Pawel J, et al. Phase III study comparing cisplatin plus gemcitabine with cisplatin plus pemetrexed in chemotherapy-naive patients with advanced-stage non-small-cell lung cancer. J Clin Oncol 2008; 26: 3543-3551.

8 Shepherd FA, Rodrigues Pereira J, Ciuleanu T, et al. Erlotinib in previously treated non-small-cell lung cancer. N Engl J Med 2005; 353: 123-132. 
9 Kim ES, Hirsh V, Mok T, et al. Gefitinib versus docetaxel in previously treated non-small-cell lung cancer (INTEREST): a randomised phase III trial. Lancet 2008; 372: 1809-1818.

10 Douillard J-Y, Shepherd FA, Hirsh V, et al. Molecular predictors of outcome with gefitinib and docetaxel in previously treated non-small-cell lung cancer: data from the randomized phase III INTEREST trial. $J$ Clin Oncol 2010; 28: 744-752.

11 Ciuleanu T, Stelmakh L, Cicenas S, et al. Efficacy and safety of erlotinib versus chemotherapy in second-line treatment of patients with advanced, non-small-cell lung cancer with poor prognosis (TITAN): a randomised multicentre, open-label, phase 3 study. Lancet Oncol 2012; 13: 300-308.

12 Sun J-M, Lee KH, Kim S, et al. Gefitinib versus pemetrexed as second-line treatment in patients with nonsmall cell lung cancer previously treated with platinum-based chemotherapy (KCSG-LU08-01): an open-label, phase 3 trial. Cancer 2012; 118: 6234-6242.

13 Garassino MC, Martelli O, Broggini M, et al. Erlotinib versus docetaxel as second-line treatment of patients with advanced non-small-cell lung cancer and wild-type EGFR tumours (TAILOR): a randomised controlled trial. Lancet Oncol 2013; 14: 981-988.

14 Kawaguchi T, Ando M, Asami K, et al. Randomized phase III trial of erlotinib versus docetaxel as second- or third-line therapy in patients with advanced non-small-cell lung cancer: Docetaxel and Erlotinib Lung Cancer Trial (DELTA). J Clin Oncol 2014; 32: 1902-1908.

15 Karampeazis A, Voutsina A, Souglakos J, et al. Pemetrexed versus erlotinib in pretreated patients with advanced non-small cell lung cancer: a Hellenic Oncology Research Group (HORG) randomized phase 3 study. Cancer 2013; 119: 2754-2764.

16 Lee J-K, Hahn S, Kim D-W, et al. Epidermal growth factor receptor tyrosine kinase inhibitors vs conventional chemotherapy in non-small cell lung cancer harboring wild-type epidermal growth factor receptor: a meta-analysis. JAMA 2014; 311: 1430-1437.

17 Maruyama R, Nishiwaki Y, Tamura T, et al. Phase III study, V-15-32, of gefitinib versus docetaxel in previously treated Japanese patients with non-small-cell lung cancer. J Clin Oncol 2008; 26: 4244-4252.

18 Zhao N, Zhang X-C, Yan H-H, et al. Efficacy of epidermal growth factor receptor inhibitors versus chemotherapy as second-line treatment in advanced non-small-cell lung cancer with wild-type EGFR: a meta-analysis of randomized controlled clinical trials. Lung Cancer 2014; 85: 66-73.

19 Yang J, Cheng Y, Zhao M, et al. A phase II trial comparing pemetrexed with gefitinib as the second-line treatment of nonsquamous NSCLC patients with wild-type EGFR (CTONG0806). J Clin Oncol 2013; 31: Suppl., 8042.

20 Lilenbaum R, Herndon J, List M, et al. Single-agent versus combination chemotherapy in advanced non-small cell lung cancer (NSCLC): a CALGB randomized trial of efficacy, quality of life, and cost-effectiveness. Eur J Cancer 2001; 37: S153-S154.

21 Le Chevalier T, Brisgand D, Douillard JY, et al. Randomized study of vinorelbine and cisplatin versus vindesine and cisplatin versus vinorelbine alone in advanced non-small-cell lung cancer: results of a European multicenter trial including 612 patients. J Clin Oncol 1994; 12: 360-367.

22 Takeda K, Negoro S, Tamura T, et al. Phase III trial of docetaxel plus gemcitabine versus docetaxel in second-line treatment for non-small-cell lung cancer: results of a Japan Clinical Oncology Group trial (JCOG0104). Ann Oncol 2009; 20: 835-841.

23 Pallis AG, Agelaki S, Agelidou A, et al. A randomized phase III study of the docetaxel/carboplatin combination versus docetaxel single-agent as second line treatment for patients with advanced/metastatic non-small cell lung cancer. BMC Cancer 2010; 10: 633.

24 Smit EF, Burgers SA, Biesma B, et al. Randomized phase II and pharmacogenetic study of pemetrexed compared with pemetrexed plus carboplatin in pretreated patients with advanced non-small-cell lung cancer. J Clin Oncol 2009; 27: 2038-2045.

25 Ardizzoni A, Tiseo M, Boni L, et al. Pemetrexed versus pemetrexed and carboplatin as second-line chemotherapy in advanced non-small-cell lung cancer: results of the GOIRC 02-2006 randomized phase II study and pooled analysis with the NVALT7 trial. J Clin Oncol 2012; 30: 4501-4507.

26 Pectasides D, Pectasides M, Farmakis D, et al. Comparison of docetaxel and docetaxel-irinotecan combination as second-line chemotherapy in advanced non-small-cell lung cancer: a randomized phase II trial. Ann Oncol 2005; 16: 294-299.

27 Wachters FM, Groen HJM, Biesma B, et al. A randomised phase II trial of docetaxel $v s$ docetaxel and irinotecan in patients with stage IIIb-IV non-small-cell lung cancer who failed first-line treatment. Br J Cancer 2005; 92: $15-20$.

28 Di Maio M, Chiodini P, Georgoulias V, et al. Meta-analysis of single-agent chemotherapy compared with combination chemotherapy as second-line treatment of advanced non-small-cell lung cancer. J Clin Oncol 2009; 27: 1836-1843.

29 Qi W-X, Shen Z, Yao Y. Meta-analysis of docetaxel-based doublet versus docetaxel alone as second-line treatment for advanced non-small-cell lung cancer. Cancer Chemother Pharmacol 2012; 69: 99-106.

30 Georgoulias V, Agelidou A, Syrigos K, et al. Second-line treatment with irinotecan plus cisplatin vs cisplatin of patients with advanced non-small-cell lung cancer pretreated with taxanes and gemcitabine: a multicenter randomised phase II study. Br J Cancer 2005; 93: 763-769.

31 Parmar MKB, Ledermann JA, Colombo N, et al. Paclitaxel plus platinum-based chemotherapy versus conventional platinum-based chemotherapy in women with relapsed ovarian cancer: the ICON4/AGO-OVAR-2.2 trial. Lancet 2003; 361: 2099-2106.

32 Genestreti G, Metro G, Kenmotsu H, et al. Final outcome results of platinum-sensitive small cell lung cancer (SCLC) patients treated with platinum-based chemotherapy rechallenge: a multi-institutional retrospective analysis. J Clin Oncol 2014; 32: Suppl., 7600.

33 Petrelli F, Coinu A, Cabiddu M, et al. Platinum rechallenge in patients with advanced NSCLC: a pooled analysis. Lung Cancer 2013; 81: 337-342.

34 Lee DH, Lee JS, Kim S-W, et al. Three-arm randomised controlled phase 2 study comparing pemetrexed and erlotinib to either pemetrexed or erlotinib alone as second-line treatment for never-smokers with non-squamous non-small cell lung cancer. Eur J Cancer 2013; 49: 3111-3121. 
Dittrich C, Papai-Szekely Z, Vinolas N, et al. A randomised phase II study of pemetrexed versus pemetrexed+ erlotinib as second-line treatment for locally advanced or metastatic non-squamous non-small cell lung cancer. Eur J Cancer 2014; 50: 1571-1580.

36 Kim ES, Neubauer M, Cohn A, et al. Docetaxel or pemetrexed with or without cetuximab in recurrent or progressive non-small-cell lung cancer after platinum-based therapy: a phase 3, open-label, randomised trial. Lancet Oncol 2013; 14: 1326-1336.

37 Meira DD, Nóbrega I, de Almeida VH, et al. Different antiproliferative effects of matuzumab and cetuximab in A431 cells are associated with persistent activity of the MAPK pathway. Eur J Cancer 2009; 45: 1265-1273.

38 Bier H, Hoffmann T, Haas I, et al. Anti-(epidermal growth factor) receptor monoclonal antibodies for the induction of antibody-dependent cell-mediated cytotoxicity against squamous cell carcinoma lines of the head and neck. Cancer Immunol Immunother 1998; 46: 167-173.

39 Schiller JH, von Pawel J, Schütt P, et al. Pemetrexed with or without matuzumab as second-line treatment for patients with stage IIIB/IV non-small cell lung cancer. J Thorac Oncol 2010; 5: 1977-1985.

40 Thatcher N, Hirsch FR, Szczesna A, et al. A randomized, multicenter, open-label, phase III study of gemcitabine-cisplatin (GC) chemotherapy plus necitumumab (IMC-11F8/LY3012211) versus GC alone in the first-line treatment of patients (pts) with stage IV squamous non-small cell lung cancer (sq-NSCLC). J Clin Oncol 2014; 32: Suppl., 8008.

41 Paz-Ares L, Mezger J, Ciuleanu TE, et al. Necitumumab plus pemetrexed and cisplatin as first-line therapy in patients with stage IV non-squamous non-small-cell lung cancer (INSPIRE): an open-label, randomised, controlled phase 3 study. Lancet Oncol 2015; 16: 328-337.

42 Mascaux C, Iannino N, Martin B, et al. The role of RAS oncogene in survival of patients with lung cancer: a systematic review of the literature with meta-analysis. Br J Cancer 2005; 92: 131-139.

43 Eberhard DA, Johnson BE, Amler LC, et al. Mutations in the epidermal growth factor receptor and in KRAS are predictive and prognostic indicators in patients with non-small-cell lung cancer treated with chemotherapy alone and in combination with erlotinib. J Clin Oncol 2005; 23: 5900-5909.

44 Jänne PA, Shaw AT, Pereira JR, et al. Selumetinib plus docetaxel for KRAS-mutant advanced non-small-cell lung cancer: a randomised, multicentre, placebo-controlled, phase 2 study. Lancet Oncol 2013; 14: 38-47.

45 Brahmer JR, Dahlberg SE, Gray RJ, et al. Sex differences in outcome with bevacizumab therapy: analysis of patients with advanced-stage non-small cell lung cancer treated with or without bevacizumab in combination with paclitaxel and carboplatin in the Eastern Cooperative Oncology Group Trial 4599. J Thorac Oncol 2011; 6: 103-108.

46 Adjei AA, Mandrekar SJ, Dy GK, et al. Phase II trial of pemetrexed plus bevacizumab for second-line therapy of patients with advanced non-small-cell lung cancer: NCCTG and SWOG study N0426. J Clin Oncol 2010; 28: 614-619.

47 Herbst RS, O’Neill VJ, Fehrenbacher L, et al. Phase II study of efficacy and safety of bevacizumab in combination with chemotherapy or erlotinib compared with chemotherapy alone for treatment of recurrent or refractory non small-cell lung cancer. J Clin Oncol 2007; 25: 4743-4750.

48 Habib S, Delourme J, Dhalluin X, et al. Bevacizumab and weekly paclitaxel for non-squamous non small cell lung cancer patients: a retrospective study. Lung Cancer 2013; 80: 197-202.

49 Ramlau R, Gorbunova V, Ciuleanu TE, et al. Aflibercept and docetaxel versus docetaxel alone after platinum failure in patients with advanced or metastatic non-small-cell lung cancer: a randomized, controlled phase III trial. J Clin Oncol 2012; 30: 3640-3647.

50 Garon EB, Ciuleanu T-E, Arrieta O, et al. Ramucirumab plus docetaxel versus placebo plus docetaxel for second-line treatment of stage IV non-small-cell lung cancer after disease progression on platinum-based therapy (REVEL): a multicentre, double-blind, randomised phase 3 trial. Lancet 2014; 384: 665-673.

51 de Boer RH, Arrieta Ó, Yang C-H, et al. Vandetanib plus pemetrexed for the second-line treatment of advanced non-small-cell lung cancer: a randomized, double-blind phase III trial. J Clin Oncol 2011; 29: 1067-1074.

52 Herbst RS, Sun Y, Eberhardt WE, et al. Vandetanib plus docetaxel versus docetaxel as second-line treatment for patients with advanced non-small-cell lung cancer (ZODIAC): a double-blind, randomised, phase 3 trial. Lancet Oncol 2010; 11: 619-626.

53 Heymach JV, Johnson BE, Prager D, et al. Randomized, placebo-controlled phase II study of vandetanib plus docetaxel in previously treated non small-cell lung cancer. J Clin Oncol 2007; 25: 4270-4277.

54 Heymach JV, Lockwood SJ, Herbst RS, et al. EGFR biomarkers predict benefit from vandetanib in combination with docetaxel in a randomized phase III study of second-line treatment of patients with advanced non-small cell lung cancer. Ann Oncol 2014; 25: 1941-1948.

55 Hanna NH, Kaiser R, Sullivan RN, et al. Lume-lung 2: a multicenter, randomized, double-blind, phase III study of nintedanib plus pemetrexed versus placebo plus pemetrexed in patients with advanced nonsquamous non-small cell lung cancer (NSCLC) after failure of first-line chemotherapy. J Clin Oncol 2013; 31: Suppl., 8034.

56 Reck M, Kaiser R, Mellemgaard A, et al. Docetaxel plus nintedanib versus docetaxel plus placebo in patients with previously treated non-small-cell lung cancer (LUME-Lung 1): a phase 3, double-blind, randomised controlled trial. Lancet Oncol 2014; 15: 143-155.

57 Chiappori A, Bepler G, Barlesi F, et al. Phase II, double-blinded, randomized study of enzastaurin plus pemetrexed as second-line therapy in patients with advanced non-small cell lung cancer. J Thorac Oncol 2010; 5: 369-375.

58 Herbst RS, Ansari R, Bustin F, et al. Efficacy of bevacizumab plus erlotinib versus erlotinib alone in advanced non-small-cell lung cancer after failure of standard first-line chemotherapy (BeTa): a double-blind, placebo-controlled, phase 3 trial. Lancet 2011; 377: 1846-1854.

59 Socinski MA, Novello S, Sanchez JM, et al. Efficacy and safety of sunitinib in previously treated, advanced non-small cell lung cancer (NSCLC): preliminary results of a multicenter phase II trial. J Clin Oncol 2006; 24: Suppl., 7001.

60 Scagliotti GV, Krzakowski M, Szczesna A, et al. Sunitinib plus erlotinib versus placebo plus erlotinib in patients with previously treated advanced non-small-cell lung cancer: a phase III trial. J Clin Oncol 2012; 30: 2070-2078.

61 Schiller JH, Lee JW, Hanna NH, et al. A randomized discontinuation phase II study of sorafenib versus placebo in patients with non-small cell lung cancer who have failed at least two prior chemotherapy regimens: E2501. J Clin Oncol 2008; 26: Suppl., 8014. 
62 Spigel DR, Burris HA, Greco FA, et al. Randomized, double-blind, placebo-controlled, phase II trial of sorafenib and erlotinib or erlotinib alone in previously treated advanced non-small-cell lung cancer. J Clin Oncol 2011; 29: 2582-2589.

63 Papadimitrakopoulou V. Development of PI3K/AKT/mTOR pathway inhibitors and their application in personalized therapy for non-small-cell lung cancer. J Thorac Oncol 2012; 7: 1315-1326.

64 Soria J-C, Shepherd FA, Douillard J-Y, et al. Efficacy of everolimus (RAD001) in patients with advanced NSCLC previously treated with chemotherapy alone or with chemotherapy and EGFR inhibitors. Ann Oncol 2009; 20: 1674-1681.

65 Price KA, Azzoli CG, Krug LM, et al. Phase II trial of gefitinib and everolimus in advanced non-small cell lung cancer. J Thorac Oncol 2010; 5: 1623-1629.

66 Besse B, Leighl N, Bennouna J, et al. Phase II study of everolimus-erlotinib in previously treated patients with advanced non-small-cell lung cancer. Ann Oncol 2014; 25: 409-415.

67 Go H, Jeon YK, Park HJ, et al. High MET gene copy number leads to shorter survival in patients with non-small cell lung cancer. J Thorac Oncol 2010; 5: 305-313.

68 Sequist LV, von Pawel J, Garmey EG, et al. Randomized phase II study of erlotinib plus tivantinib versus erlotinib plus placebo in previously treated non-small-cell lung cancer. J Clin Oncol 2011; 29: 3307-3315.

69 Scagliotti GV, Novello S, Schiller JH, et al. Rationale and design of MARQUEE: a phase III, randomized, double-blind study of tivantinib plus erlotinib versus placebo plus erlotinib in previously treated patients with locally advanced or metastatic, nonsquamous, non-small-cell lung cancer. Clin Lung Cancer 2012; 13: 391-395.

70 Ramalingam SS, Spigel DR, Chen D, et al. Randomized phase II study of erlotinib in combination with placebo or R1507, a monoclonal antibody to insulin-like growth factor-1 receptor, for advanced-stage non-small-cell lung cancer. J Clin Oncol 2011; 29: 4574-4580.

71 Witta SE, Jotte RM, Konduri K, et al. Randomized phase II trial of erlotinib with and without entinostat in patients with advanced non-small-cell lung cancer who progressed on prior chemotherapy. J Clin Oncol 2012; 30: $2248-2255$

72 Lynch TJ, Fenton D, Hirsh V, et al. A randomized phase 2 study of erlotinib alone and in combination with bortezomib in previously treated advanced non-small cell lung cancer. J Thorac Oncol 2009; 4: 1002-1009.

73 Qi W-X, Wang Q, Jiang Y-L, et al. Overall survival benefits for combining targeted therapy as second-line treatment for advanced non-small-cell-lung cancer: a meta-analysis of published data. PLoS One 2013; 8: e55637.

74 Planchard D, Mazieres J, Riely GJ, et al. Interim results of phase II study BRF113928 of dabrafenib in BRAF V600E mutation-positive non-small cell lung cancer (NSCLC) patients. J Clin Oncol 2013; 31: Suppl., 8009.

75 Mazières J, Peters S, Lepage B, et al. Lung cancer that harbors an HER2 mutation: epidemiologic characteristics and therapeutic perspectives. J Clin Oncol 2013; 31: 1997-2003.

76 Lynch TJ, Bondarenko I, Luft A, et al. Ipilimumab in combination with paclitaxel and carboplatin as first-line treatment in stage IIIB/IV non-small-cell lung cancer: results from a randomized, double-blind, multicenter phase II study. J Clin Oncol 2012; 30: 2046-2054.

77 Topalian SL, Hodi FS, Brahmer JR, et al. Safety, activity, and immune correlates of anti-PD-1 antibody in cancer. N Engl J Med 2012; 366: 2443-2454.

78 Rizvi NA, Mazières J, Planchard D, et al. Activity and safety of nivolumab, an anti-PD-1 immune checkpoint inhibitor, for patients with advanced, refractory squamous non-small-cell lung cancer (CheckMate 063): a phase 2, single-arm trial. Lancet Oncol 2015; 16: 257-265.

79 Bristol Myers Squibb. CheckMate -017, a Phase 3 Study of Opdivo (Nivolumab) Compared to Docetaxel in Patients with Second-Line Squamous Cell Non-small Cell Lung Cancer, Stopped Early. http://news.bms.com/ press-release/checkmate-017-phase-3-study-opdivo-nivolumab-compared-docetaxel-patients-second-line-s Date last accessed: March 23, 2015.

80 Soria JC, Cruz C, Bahleda R, et al. Clinical activity, safety and biomarkers of PD-L1 blockade in non-small cell lung cancer (NSCLC): additional analyses from a clinical study of the engineered antibody MPDL3280A (anti-PDL1). Eur J Cancer 2013; 49: Suppl. 2, S759-S892.

81 Quoix E, Ramlau R, Westeel V, et al. Therapeutic vaccination with TG4010 and first-line chemotherapy in advanced non-small-cell lung cancer: a controlled phase 2B trial. Lancet Oncol 2011; 12, 1125-1133.

82 Neninger Vinageras E, de la Torre A, Osorio Rodríguez M, et al. Phase II randomized controlled trial of an epidermal growth factor vaccine in advanced non-small-cell lung cancer. J Clin Oncol 2008; 26: 1452-1458. 